\title{
SABERES TRADICIONAIS, BIODIVERSIDADE, PRÁTICAS INTEGRATIVAS E COMPLEMENTARES: O USO DE PLANTAS MEDICINAIS NO SUS
}

\section{TRADITIONAL KNOWLEDGE, BIODIVERSITY, INTEGRATIVE AND COMPLEMENTARY PRACTICES: THE USE OF MEDICINAL PLANTS IN THE SUS}

\author{
Marta Rocha de Castro \\ Mestra em Psicossociologia (UFRJ) \\ Doutoranda em Geografia (PUC-RIO) \\ martarochaacupuntura@gmail.com \\ Fábio Fonseca Figueiredo \\ Doutor em Geografia Humana (Universidade de Barcelona/Espanha) \\ Professor do Departamento de Políticas Públicas, Universidade Federal do Rio Grande do Norte (UFRN) \\ ffabiof@yahoo.com
}

\begin{abstract}
RESUMO
O artigo tem como objetivo apresentar o uso de plantas medicinais no âmbito da Política Nacional de Práticas Integrativas e Complementares implementada no Sistema Único de Saúde desde 2006. Realizamos uma revisão bibliográfica do tema, sobretudo na área da geografia da saúde, bem como a consulta a documentos produzidos e distribuídos pelo Governo Federal, através do Ministério da Saúde. Conforme resultados, a prática do uso das plantas medicinais é fortemente recomendada pelos organismos internacionais e a sua institucionalização através Política Nacional de Plantas Medicinais e Fitoterápicos valoriza sobremaneira os saberes tradicionais no cuidado à saúde adquiridos ao longo dos séculos. $\mathrm{O}$ fato das pesquisas cientificas comprovarem através de métodos da medicina moderna a eficiência no uso das plantas medicinais reforça tais saberes no uso dessas plantas nas unidades atenção à saúde básica. Outro aspecto satisfatório é proporcionar um maior conhecimento da biodiversidade do país haja vista que as plantas utilizadas no tratamento a doentes serem regionalizadas. Assim, o uso das plantas medicinais na atenção à saúde básica implica numa forma de tratamento médico diferenciado da medicina praticada atualmente, que se baseia amplamente em métodos cientificistas onde a tecnologia se sobressai à prática médica fundamentada na precaução e prevenção.
\end{abstract}

Palavras-Chave: Conhecimento tradicional. Medicina alternativa. Política Nacional de Plantas Medicinais e Fitoterápicos.

\section{ABSTRACT}

The article aims to present the use of medicinal plants within the scope of the National Policy on Integrative and Complementary Practices implemented in the Unified Health System since 2006. We have carried out a wide bibliographic review of the theme, especially in the area of health geography, as well as the consultation to documents produced and distributed by the Federal Government, through the Ministry of Health. According to results, the practice of the use of medicinal plants is strongly recommended by the international organisms and its institutionalization through National Policy of Medicinal Plants and Herbal Medicine values the traditional health care knowledge gained over the centuries. The fact that scientific research proves through methods of modern medicine the efficiency in the use of medicinal plants reinforces such knowledge in the use of these plants in basic health care units. Another satisfactory aspect is to provide greater knowledge of the country's biodiversity since the plants used in the treatment of patients are regionalized. Thus, the use of medicinal plants in basic health care implies a form of medical treatment differentiated from the medicine practiced today, which is based largely on scientific methods where the technology excels at medical practice based on precaution and prevention.

Key-words: Traditional knowledge. Alternative medicine. National Policy of Medicinal Plants and Herbal Medicines.

Recebido em: 08/01/2019

Aceito para publicação em: 27/05/2019 


\section{INTRODUÇÃO}

Quando os colonizadores europeus chegaram ao Brasil, ainda no século XV, encontraram os povos autóctones e estes apresentavam práticas de saúde próprias, entre elas o uso das plantas medicinais facilmente encontradas no seu entorno (FREITAS, 2014). Com o passar dos séculos, a exploração desordenada da rica biodiversidade motivada pelos ciclos econômicos impostos pelos lusitanos, e posteriormente pela elite do Império brasileiro, deixou consequências nocivas ao meio ambiente relacionadas a extinção de espécies nativas, desmatamentos, contaminações de ecossistemas, o que implicaria em novas e diversas formas de convivência da população local com a biodiversidade. Essa forma de intervenção na natureza também contribuiu para que as práticas médicas secularmente conhecidas fossem adaptadas e/ou substituídas pela medicina moderna, além de servir de alerta para as consequências nefastas para o meio ambiente (TABARELLI et al., 2010).

A medicina praticada na Europa, conhecida hoje como medicina moderna, aos poucos foi sendo imposta pelo colonizador como a principal forma de tratamento médico a ser seguido justamente por ser passível comprovação científica. Assim, as demais formas de cuidado, autocuidado, tratamento e cura dos povos autóctones, por não serem comprovadas conforme a lógica cientificista da medicina positivista europeia, foram encaradas como primitivas, ultrapassadas e, muitas vezes, desqualificadas pejorativamente como manifestações de crendices populares e charlatanismo (FREITAS, 2014; LUZ, 2005).

A partir da década de 1970, os organismos internacionais começaram a se interessar pelas práticas medicinais qualificadas, então, como tradicionais, que difundidas pela globalização, tornaram-se coqueluche no que concerne ao cuidado e atenção à saúde humana. $O$ interesse mundial pelos conhecimentos e práticas tradicionais nas últimas décadas fizeram parte de diversos debates públicos e que, muitos deles, concretizaram-se em políticas públicas, aí incluindo a Política Nacional de Plantas Medicinais e Fitoterápicos do governo brasileiro que se configura em uma institucionalização do saber popular e tradicional, na disseminação do conhecimento da biodiversidade nacional e no fomento à indústria farmacêutica nacional.

Este artigo, que se insere no campo da geografia da saúde, faz uma reflexão da trajetória do uso das plantas medicinais na atenção básica de saúde no Brasil a partir dos saberes tradicionais ressaltando a importância do conhecimento da natureza para a preservação da biodiversidade. Na seção seguinte a esta introdução, iniciamos a fundamentação teórica fazendo um breve resgate sócio-histórico da relação entre os usos dos recursos da biodiversidade pelos povos autóctones e a influência da colonização lusitana na formação do sistema de saúde brasileiro. Na terceira parte, o artigo apresenta e analisa o interesse de órgãos internacionais pelas medicinas tradicionais, que se revelam nas recomendações para que os países formulem nas suas políticas nacionais de saúde as práticas, sabes e conhecimentos dos povos nativos. Ainda, daremos especial ênfase à institucionalização das práticas integrativas e complementares na política de saúde do governo brasileiro. A quarta seção trata exclusivamente da Política Nacional de Plantas Medicinais e Fitoterápicos do Brasil, elencando seus aspectos normativos, geomorfológicos e medicinais. Em seguida, destacaremos os resultados e discussão apresentando a categorização das plantas medicinais realizada pelo Programa de Pesquisa e Plantas Medicinais onde mostramos a efetividade do uso e toxidade das espécies analisadas. Por fim, as considerações finais apresentam uma síntese analítica do que foi apresentado ao longo do texto.

\section{BIODIVERSIDADE E A INFLUÊNCIA DA COLONIZAÇÃO LUSITANA NA FORMAÇÃO DO SISTEMA DE SAÚDE BRASILEIRO}

No início da ocupação do território brasileiro pelos portugueses nos séculos $\mathrm{XV}$ e $\mathrm{XVI}$, o Brasil era povoado majoritariamente por povos autóctones de denominação tupiniquim. Posteriormente, devido ao crescimento demográfico e a consequente disputa por territórios com melhores condições de plantio, pesca e caça esses povos se expandiram e se dividiram em duas etnias maiores: os tupis e os guaranis e, no momento seguinte, deram origem a outras etnias (FREITAS, 2014).

Os povos autóctones, que chamaremos de índios, apresentavam modos de vida, cultura e uma relação com a natureza distinta dos portugueses. As tensões e as trocas que permearam esse encontro de culturas é narrado de maneira satisfatória por Blaj e Maluf (1990), quando as autoras analisaram o sexto capítulo da obra de Sérgio Buarque de Holanda "Biótica da natureza". As autoras relacionam o meio, a sociedade e a cultura a partir do cotidiano vivido pelo encontro de culturas 
distintas. Essa análise nos remeteu a uma possibilidade de inferir sobre a trajetória da utilização das plantas medicinais na política de saúde no Brasil.

Os índios encontrados pelos colonizadores europeus possuíam o que podemos caracterizar de um sistema de saúde próprio, e as plantas medicinais eram um importante elemento desse sistema devido seu uso para fins de cura a enfermidades. Em uma relação de pertencimento e dependência da natureza, os índios eram detentores de conhecimentos de cultivos e ciclos da natureza já que dependiam diretamente dela para a sobrevivência, como época de plantio e colheita, pesca e o saber sobre as plantas medicinais (DIEGUES et al., 1999).

Em um primeiro momento, os colonizadores europeus precisaram se adaptar aos costumes indígenas como forma de estratégia de sobrevivência no ainda desconhecido território (BRAJ e MALUF, 1990). Os hábitos indígenas constituíram parte importante na formação do setor de saúde no Brasil Colônia, uma vez que tais hábitos foram incorporados pelos colonizadores, no primeiro momento, e pelas demais etnias que povoavam a então colônia lusitana.

O primeiro relato sócio-antropológico dos costumes indígenas no Brasil foi realizado pelo alemão Hans Staden (2010) em "Duas viagens ao Brasil: primeiros registros sobre o Brasil", obra considerada um clássico nas primeiras décadas do século XVI. Nesse livro há relatos sobre a exuberância e potencialidades da natureza bem como apresenta e detalha os modos de vida, crendices, xamanismo, festas e cotidianidade dos nativos do novo e até então desconhecido mundo. A figura 1, retirado da obra citada, apresenta desenhos do autor quando ele narra a vida nas comunidades indígenas.

Figura 1: Desenhos feitos por Hans Staden durante suas duas viagens ao Brasil Colônia

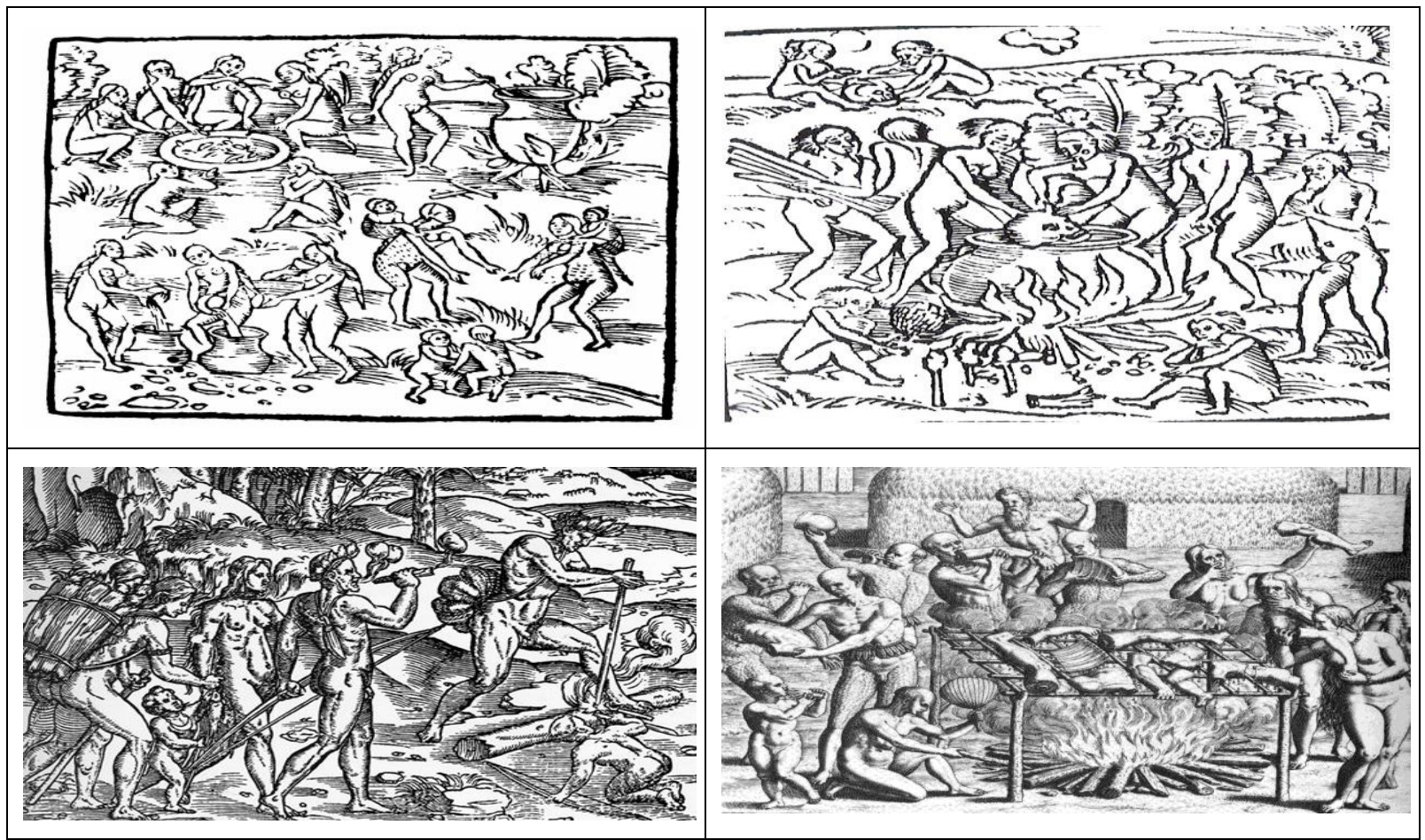

Fonte: Staden (2010)

A maleabilidade dos portugueses favoreceu a sua adaptação à cultura indígena no novo território. Após a aproximação inicial, houve a necessidade de assimilação, que para Blaj e Maluf (1990, p. 22) significou, portanto "numa consciência do outro que é o portador de uma sabedoria que deve ser conquistada/assimilada". E, no que se revela posteriormente numa apropriação do conhecimento do outro.

$\mathrm{Na}$ Europa renascentista, as informações sobre o corpo e a saúde eram baseadas nas técnicas desenvolvidas por Hipócrates, considerado o pai da medicina na Grécia Antiga. Freitas (2014) 
comentou que nas teorias hipocráticas, o organismo humano era compreendido com base em quatro humores corporais (sangue, fleugma ou pituíta, bílis amarela e bílis negra). E nesta concepção de corpo e saúde, a doença era concebida como o desequilíbrio desses líquidos, sendo, portanto, algo estritamente relacionado ao orgânico e simplificado ao perfeito funcionamento do organismo humano.

A medicina hipocrática praticada na Europa no período dos descobrimentos em muito se diferenciava das concepções de saúde, doença e tratamento praticada pelas comunidades indígenas do Novo Mundo. Hipócrates lançou, talvez, as bases de uma abordagem racional para a medicina, na qual as verificações, diagnósticos e receitas para a cura das enfermidades deveriam ser fundamentadas em complexos e extensos estudos científicos. Diferentemente, a etnomedicina (ALHO, 2012) praticada pelas comunidades indígenas se baseava em concepções/definições tais como os símbolos do adoecimento atravessando o fator estritamente orgânico e biológico corporal, perpassando pelas dimensões espirituais e transcendentais.

A Igreja Católica enquanto instituição teve importante influência no sistema de saúde de Portugal através do campo assistencial, que até o século XV era realizado em mosteiros e enfermarias dos conventos. Até então, não havia médicos e os cuidados aos enfermos eram realizados por botânicos e físicos, enquanto que no mesmo período, no Brasil, os pajés das comunidades indígenas cumpriam o papel do cuidado aos doentes (FREITAS, 2014). A Igreja Católica também influenciou na formação do sistema de saúde no Brasil Colônia através da ordem religiosa Companhia de Jesus dos Jesuítas², que vieram inicialmente com a missão de evangelização dos povos pagãos, porém foram de extrema importância para os índios, pois estudaram as plantas conhecidas à época, fundaram as Santas Casas de Misericórdia e ajudaram nos tratamentos de saúde de índios afetados pelas novas enfermidades trazidas pelos europeus, colonizadores e brasileiros3.

Blaj e Maluf (1990) explicaram que os portugueses criaram uma farmacopeia popular, unindo o conhecimento indígena sobre as plantas, em uma fusão de saber com a natureza e a alquimia europeia, numa relação de oposição e poder do homem sobre a natureza. E, a apropriação do conhecimento nativo (bárbaro) pelo europeu se revelou quando se adquiriu conhecimento de uma gama de medicamentos fármacos europeus, que já eram utilizados pelas comunidades indígenas brasileiras antes da chegada dos colonizadores.

Este movimento contínuo, dinâmico e carregado de tensões que marcou as primeiras décadas do período colonial brasileiro começou a ter um rompimento quando, aos poucos e lentamente, elementos da cultura europeia tais como os costumes, as práticas e os saberes passaram a compor o cotidiano na colônia (FREITAS, 2014). O legado da colonização e o consequente eurocentrismo, analisa Lander (2005), afetou não somente as relações culturais e sociais, mas o campo epistemológico da vida na colônia, ou seja, as outras formas de vida e sociabilidades deveriam ser a base da cotidianidade, o que necessariamente implicaria no rompimento com as heranças e costumes ditos primitivos.

Nos séculos seguintes ao início da colonização, (XVI e XVII), os interesses pela anatomia e a influência cartesiana e cristã dominaram o campo médico no velho continente (DONATELLI, 2003). Já no século XVIII, e sobretudo no século XIX, a medicina praticada na Europa sob forte influência positivista obteve uma enorme expansão motivada pelo uso de implementos tecnológicos, período esse marcado pela Revolução Científica e a consequente revolução industrial (QUEIROZ, 1986).

Foucault (1978) nos remeteu, ainda, a outro aspecto ao relacionar o avanço da medicina europeia a partir do século das luzes, relacionando-o ao surgimento e desenvolvimento do sistema capitalista de produção e a sua avareza pela exploração, domínio e extermínio a tudo que não se adeque aos seus interesses:

O que o século XVIII mostra, em todo o caso, são duas faces de um mesmo processo: o desenvolvimento de um mercado médico sob a forma de clientelas

\footnotetext{
2 Um belo e fiel relato da importância dos Jesuítas para a formação do que posteriormente veio a ser o sistema de saúde brasileiro está no filme "A Missão", de 1986, dirigido pelo cineasta franco-britânico Roland Joffé.

${ }^{3}$ Conforme Alho (2012), os primeiros conquistadores europeus que desembarcaram no Novo Mundo nos séculos XV e XVI trouxeram doenças infecciosas como varíola e tifo, que dizimaram cerca de 50 milhões de índios em três séculos.
} 
privadas, a extensão de uma rede de pessoal que oferece intervenções medicamente qualificadas, o aumento de uma demanda de cuidados por parte dos indivíduos e das famílias, a emergência de uma medicina clínica fortemente centrada no exame, no diagnóstico, na terapêutica individuais, a exaltação explicitamente moral e científica (secretamente econômica) do "colóquio singular", em suma, o surgimento progressivo da grande medicina do século XIX não pode ser dissociado da organização, na mesma época, de uma política da saúde e de uma consideração das doenças como problema político e econômico, que se coloca às coletividades e que elas devem tentar resolver ao nível de suas decisões de conjunto (p. 170).

As demais práticas medicinais consideradas ultrapassadas, e mesmo primitivas, que possuíam uma sistemática própria de funcionamento e que não comprovavam as suas práticas pelos mesmos métodos científicos da medicina dominante, passaram a ser qualificadas como tradicionais. Para Lander (2005), a diferença entre as medicinas modernas e as medicinas primitivas/tradicionais fez que:

Ao se referirem as práticas destes povos como "tradicionais ou não modernas, como em processo de transição a modernidade nega-lhes toda a possibilidade de lógicas culturais ou cosmovisões próprias". Ao colocá-las como expressão do passado nega-se sua contemporaneidade (p. 15).

O conceito de tradicional é complexo e o seu significado vai além de "não ser moderno". Sem nos aprofundarmos no debate embora reconheçamos a sua importância para a compreensão do nosso objeto de estudo, temos que no Brasil há um conceito para as populações indígenas que as distingue das populações não indígenas. Para Diegues (et al., 1999), o termo populações indígenas possui um significado estritamente étnico, pois implicam em povos que guardam uma continuidade históricocultural adquiridos antes da conquista europeia ao Novo Mundo, ou seja, desde o período précolombiano.

Diegues (et al., 1999) elencaram características que estão presentes nos povos tradicionais, quais sejam: 1) uma relação de conhecimento e simbiose com a natureza; 2) uma relação de moradia e pertencimento a um determinado território; 3) reduzida acumulação, possuindo como base a cooperação social; e, 4) auto identificação de pertencimento à uma cultura distinta das outras. Para os autores citados, a manutenção da diversidade biológica tornou-se nos anos recentes, um dos objetivos mais importantes da conservação e preservação da natureza. Assim, a apropriação do conhecimento tradicional é de fundamental importância para a manutenção da biodiversidade.

O reconhecimento da valoração dos ecossistemas naturais e do imenso potencial que as espécies possuem para a vida humana em geral e como fonte potencial de fármacos em particular levou ao maior interesse pelas formas de uso de medicinas não convencionais (ALHO, 2012). Portanto, o uso das plantas medicinais e de medicinas tradicionais entrou na agenda das políticas públicas nas últimas décadas, sendo pauta de congressos internacionais a importância de tais usos e práticas bem como sendo fortemente recomendado a institucionalização de seus usos e aplicações diversas.

Nesse sentido, e entendendo a complexidade do termo tradicional para definir populações, digamos, não eurocêntricas no que concerne aos seus hábitos e sociabilidades, na seção seguinte iremos abordar a institucionalização dos saberes e conhecimentos tradicionais que se revela na forma de políticas públicas a partir do último quartel do século $X X$. Daremos especial enfoque à institucionalização dessas políticas no sistema público de saúde brasileiro.

\section{A INSTITUCIONALIZAÇÃO DAS PRÁTICAS, SABES E CONHECIMENTOS TRADICIONAIS NO BRASIL}

As décadas de 1960 e 1970 foram marcadas por tensões sociais que resultaram em movimentos de contracultura que se formavam no seio dos países ocidentais. Esses movimentos questionavam o modelo de reprodução da vida em uma sociedade capitalista, fundamentada fortemente pela produção e consumo de bens e serviços, formas de vida padronizadas bem como a elevada contaminação ambiental global (FIGUEIREDO, 2018). No âmbito da saúde, foram marcantes a atuação de diversos coletivos, entre eles o "Movimento Social Urbano" que se iniciou nos anos 1960 e se prolongou na década seguinte nos Estados Unidos e na Europa (LUZ, 2005).

No Brasil, foi notória a ação do movimento pela "Reforma Sanitária Brasileira" (RSB), um movimento social e democrático que em pleno regime militar teve como proposta, dentre outras pautas de 
reivindicação, a melhoria das condições de saúde da população. Para Paim (2008), o RSB contemplava a ideia de saúde como direito social, o que alicerçou a democratização da saúde no país com a Constituição Federal de 1988, sistematizando princípios e proposições políticas que posteriormente seriam as bases do atual sistema de saúde público do país.

Com aproximações e distanciamentos nas suas pautas reivindicativas, dependendo das especificidades locais de onde aconteciam, no que tange à saúde, esses movimentos de contracultura lutavam pela universalização e maior democratização da atenção à saúde básica, por melhores condições de saúde das populações, especialmente da população socioeconomicamente mais vulnerável. Ainda, esses movimentos pediam a introdução de práticas integrativas e tradicionais nos sistemas oficiais de saúde pública dos seus países.

A institucionalização dessas demandas sociais para o setor da saúde ocorreu no final dos anos 1970, quando a Organização Mundial de Saúde (OMS) e a Organização Pan-Americana de Saúde (OPAS) se interessaram pelo uso dessas medicinas e criaram o "Programa de Medicina Tradicional". O objetivo desse programa era o de estimular a formulação e implementação de políticas públicas nessa área. Conforme Saad e Lima (2010):

Desde então, em vários comunicados e resoluções, a OMS expressa o seu compromisso em incentivar os Estados-membros a formular e implementar políticas públicas para uso racional e integrado da Medicina tradicional e de terapias complementares nos sistemas nacionais de atenção à saúde básica, bem como para o desenvolvimento de estudos científicos para melhor conhecimento de sua segurança, eficácia e qualidade (p. 210).

Em 1978, no Cazaquistão (ex república da União Soviética), aconteceu a Conferência Internacional sobre Cuidados Primários de Saúde, e nesse evento foi elaborado o documento Alma-Ata. A declaração Alma-Ata reconheceu a colaboração dos praticantes das medicinas tradicionais nos cuidados primários na saúde e recomendou aos estados-membro:

A formulação de políticas e regulamentações nacionais referentes à utilização de remédios tradicionais de eficácia comprovada e exploração das possibilidades de se incorporar os detentores de conhecimento tradicional às atividades de atenção primária em saúde, fornecendo-Ihes treinamento correspondente (CMDSS, 2011).

Houve, portanto, uma forte recomendação para que nas políticas públicas dos países membros da OMS existissem o incentivo ao tratamento de doenças baseado também nas práticas das medicinas tradicionais. Já naquela época havia o entendimento que as práticas integrativas na saúde incluíam não somente as medicinas orientais e/ou as medicinas tradicionais regionais e populares, mas a medicina homeopática:

A Organização Mundial de Saúde (OMS), em conjunto com outros organismos internacionais como a organização Pan-Americana de Saúde (OPAS) recomenda que os Estados nacionais considerem os recursos e os praticantes das medicinas tradicionais na organização da atenção primária à saúde, tendo em vista a melhoria das condições de saúde da população (FERREIRA, 2013, p 33).

O interesse por essa modalidade de saúde foi reforçado em 2002 através do documento "Estratégia da OMS sobre Medicina Tradicional 2002-2005", que reafirmou o desenvolvimento de políticas observando os requisitos de segurança, eficácia, qualidade, uso racional e acesso a tais práticas (MINISTÉRIO DA SAÚDE, 2005). No ano de 2014, a OMS lançou o novo documento "A Estratégia da OMS sobre Medicina Tradicional", para o período compreendido entre 2014-2023, e nesse documento a entidade revalidou o seu interesse pelo desenvolvimento de políticas de saúde pública formuladas através de práticas medicinais tradicionais, tendo como foco:

\begin{abstract}
A ajuda às autoridades sanitárias a encontrar soluções que propiciam uma visão mais ampla a respeito da melhora da saúde e a autonomia dos pacientes. A estratégia tem dois objetivos principais: prestar apoio aos Estados Membros para que aproveitem a possível contribuição da MTC a saúde, bem-estar e a atenção centrada nas pessoas, e promover a utilização segura e eficaz da MTC mediante a regulamentação de produtos, práticas e professionais (OMS, 2014).
\end{abstract}

No âmbito brasileiro, no ano de 1986 foi realizada a $8^{\text {a }}$ Conferência Nacional de Saúde, evento considerado de fundamental importância para a elaboração do artigo 196 da Constituição Federal de 1988. A partir de então, o setor de saúde ganhou novos rumos o que culminou com a criação do Sistema Único de Saúde (SUS). Saad e Lima (2010) avaliaram que o fato de se ter usado práticas 
medicinais tradicionais ainda nos anos 1980 fez o Brasil entrar para a vanguarda internacional do uso de práticas integrativas no sistema oficial de saúde.

No ano de 2006, no Brasil, foi publicada a Política Nacional de Práticas Integrativas e Complementares da Saúde (PNPICS), através da portaria oㅜ 971, de 3 de maio de 2006 (BRASIL, 2006). Essa política inseriu na Rede de Atenção à Saúde do SUS, nos seus mais de nove mil estabelecimentos que possuem as Práticas Integrativas e Complementares (PICS), abordagens de cuidado integral à população por meio de sistemas complexos e outras práticas que envolvem recursos terapêuticos diversos 4 .

As PICS atuam no fortalecimento da promoção da saúde e prevenção de doenças e são oferecidas nos postos de atenção primária da saúde em todo o país. Baseada no modelo de atitude de ampliação de acesso a atenção humanizada e centrada na integralidade do indivíduo, a PNIPIC contribui para o fortalecimento dos princípios fundamentais do SUS.

Ainda no mesmo ano, o Governo Federal aprovou a Política Nacional de Plantas Medicinais e Fitoterápicos. Eixo importante da PNPICS, na próxima seção apresentaremos os principais objetivos e diretrizes dessa política. Daremos especial enfoque às plantas medicinais que foram aprovadas pela Agência Nacional de Vigilância Sanitária (ANVISA), para uso e distribuição pelo SUS, bem como a sua respectiva categorização no que tange as formas de uso medicinal e popular, a origem, sua área de distribuição geográfica e o ecossistema de ocorrência.

\section{POLÍTICA NACIONAL DE PLANTAS MEDICINAIS E FITOTERÁPICOS}

Como observou Alho (2012), a importância da biodiversidade para o bem-estar e à saúde humana ganhou destaque no século XX quando o processo de perda da diversidade ecossistêmica alertou a humanidade para a necessidade da conservação e do uso racional dos recursos naturais. Nesse sentido, a institucionalização dos saberes, conhecimentos e práticas tradicionais foram fundamentais por normalizar a relação homem-meio ambiente, o que de certa forma conteve a intensidade do impacto ambiental causado pela ação do homem no meio natural.

Farnsworth (1988), citado por Alho (2012), apresentou uma estatística que reflete a importância das práticas integrativas e tradicionais e a relevância do uso das plantas medicinais. Segundo o autor, no final da década de 1980 estimava-se que $80 \%$ dos habitantes de países em desenvolvimento dependiam da medicina tradicional para suprir suas necessidades básicas de saúde, enquanto que $85 \%$ dos medicamentos produzidos pela medicina tradicional envolviam o uso de extratos de plantas, sendo remédios originários da natureza próxima de onde viviam esses habitantes.

O Brasil possui a maior biodiversidade do planeta e se subdivide em seis macro biomas, quais sejam: Amazônia, Caatinga, Cerrado, Mata Atlântica, Pampa e Pantanal (ver figura 2). Junte-se a esses biomas, o macro bioma marinho e outros pequenos biomas que, embora possuam uma dimensão geográfica menor, são relevantes na formação geomorfológica do país. Nesse sentido, torna-se amplamente favorável que haja o maior incentivo tanto para a maior difusão das práticas integrativas e complementares quanto para o uso das plantas medicinais encontradas ao longo dos biomas nacionais.

Para Diegues (et at., 1999), a biodiversidade não se restringe ao meio natural, mas a uma gama de relações das diferentes sociedades e culturas com a natureza. Portanto, a relação das populações tradicionais, indígenas e não indígenas, com a natureza que se caracteriza por ser de respeito, sabedoria, sendo díspares da relação de poder, dominação, expropriação e padronização impostas pelo capitalismo contemporâneo.

\footnotetext{
${ }^{4}$ O SUS oferece atualmente 29 recursos terapêuticos no rol das suas práticas integrativas nos postos de atenção básica de saúde. As práticas envolvem o termalismo Social/Crenoterapia, práticas corporais, práticas mentais, orientação alimentar e fitoterapia tradicional chinesa. São elas: ayurveda, homeopatia, Medicina Tradicional Chinesa, medicina antroposófica, plantas medicinais/fitoterapia, arteterapia, biodança, dança circular, meditação, musicoterapia, naturopatia, osteopatia, quiropraxia, reflexoterapia, Reiki, Shantala, terapia comunitária integrativa, termalismo social/crenoterapia, Yoga, apiterapia, aromaterapia, bioenergética, constelação familiar, cromoterapia, geoterapia, hipnoterapia, imposição de mãos, ozonioterapia e terapia de florais (MINISTERIO DA SAÚDE, 2018).
} 
Figura 2: Macro biomas brasileiros

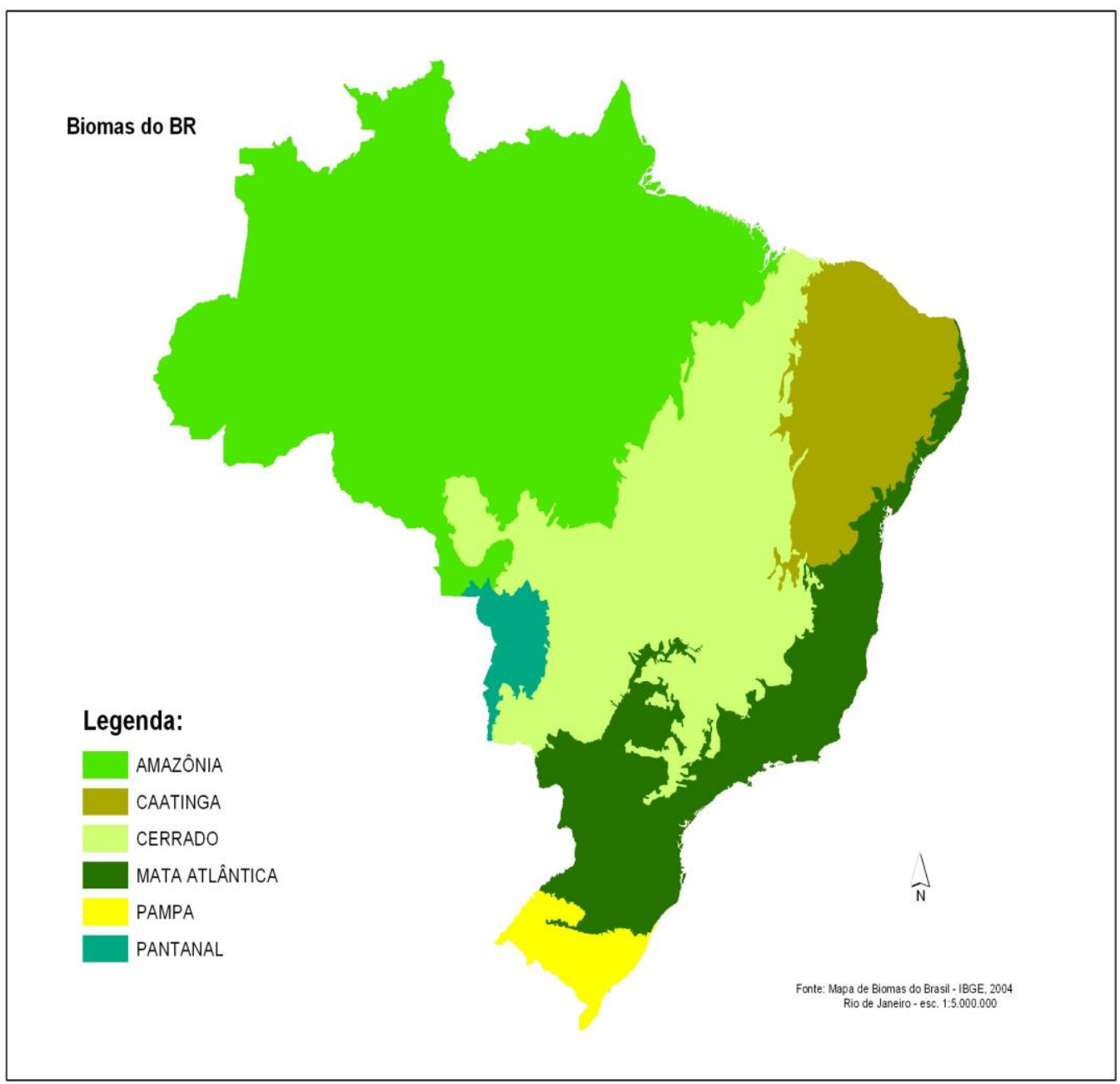

Fonte: Biodiversidade (2018)

Esta relação que coloca a natureza na condição de fornecedora de recursos com finalidades de lucro e crescimento econômico põe em risco a preservação de espécies. Assim, questões como desmatamento, extração de madeira, caça de animais silvestres entre outras são responsáveis pela extinção de diversas espécies, animais e vegetais, com rebatimentos para a espécie humana (FIGUEIREDO, 2018; ALHO, 2012). Tabarelli (et al., 2010) anunciaram que esses distúrbios provocados no ecossistema brasileiro podem ser identificados nos biomas dos quais a Mata Atlântica, reconhecida mundialmente como um dos principais hospedeiros da biodiversidade do planeta, atualmente conta com menos de $10 \%$ da sua cobertura desde a chegada dos colonizadores europeus.

Ganem (2011) informou que o Brasil hoje conta com um número expressivo de normas que dão suporte legal para a conservação, e por trás delas há trabalho de gerações de técnicos e cientistas brasileiros e estrangeiros. Contudo, Figueiredo (2018) comentou que existem avanços em matéria de política pública ambiental nacional devido a formulação de normativas ambientais que, embora questionáveis em diversos aspectos, implicam na existência de um corpo normativo que pode ser alterado conforme as demandas socioambientais.

Com o objetivo de oferecer acesso seguro ao uso das plantas medicinais e fitoterápicos, considerando a biodiversidade brasileira, o Ministério da Saúde instituiu a "Política Nacional de Plantas Medicinais e Fitoterápicos" (PNPMF) por meio do Decreto ํㅜ․ 5.813, de 22 de junho de 2006. Essa política possui como principais objetivos: 
- Ampliar as opções terapêuticas aos usuários, com garantia de acesso a plantas medicinais, fitoterápicos e serviços relacionados a fitoterapia, com segurança, eficácia e qualidade, na perspectiva da integralidade da atenção à saúde, considerando o conhecimento tradicional sobre plantas medicinais;

- Construir o marco regulatório para produção, distribuição e uso de plantas medicinais e fitoterápicos a partir dos modelos e experiências existentes no Brasil e em outros países;

- Promover pesquisa, desenvolvimento de tecnologias e inovações em plantas medicinais e fitoterápicos, nas diversas fases da cadeia produtiva

- Promover o desenvolvimento sustentável das cadeias produtivas de plantas medicinais e fitoterápicos e o fortalecimento da indústria farmacêutica nacional neste campo;

- Promover o uso sustentável da biodiversidade e a repartição dos benefícios decorrentes do acesso aos recursos genéticos de plantas medicinais e ao conhecimento tradicional associado (MINISTÉRIO DA SAÚDE, 2006, p. 21).

A PNPMF, relevante dentro da Política Nacional de Práticas Integrativas e Complementares da Saúde, considera o Brasil o país de maior biodiversidade do planeta, associada a uma rica diversidade étnica e cultural que detém um valioso conhecimento tradicional associado ao uso de plantas medicinais. A política possui como um dos seus princípios norteadores o uso sustentável da biodiversidade, o fortalecimento da produção oriunda da agricultura familiar e o incentivo à pesquisa $e$ à indústria farmacêutica nacional (MINISTÉRIO DA SAÚDE, 2006).

Apesar da PNPMF ter sido instituída somente no ano de 2006, a investigação sobre a eficácia e comprovação cientifica das plantas medicinais ocorre desde 1981 no país, através da Central de Medicamentos (CEME)5, órgão vinculado ao Ministério da Saúde e que pretendia pesquisar a toxidade e os benefícios das plantas medicinais, demonstrando a emergente atração por essas práticas no final da década de 1970 e início de 1980. No ano de 1997 a CEME foi extinta e então as pesquisas sobre plantas medicinais foram atribuídas ao Programa de Pesquisas de Plantas Medicinais (PPPM). Este programa do Ministério da Saúde possuiu como importantes participantes a ANVISA e o Laboratório Farmacêutico Federal Farmanguinhos, administrado pela Fundação Oswaldo Cruz (FIOCRUZ).

No ano de 1982 a CEME pesquisou 74 espécies, contudo quase nenhum resultado obtido pelas pesquisas foi publicado. A PPPM selecionou espécies, realizou triagens e descreveu os resultados, não divulgados, das espécies vegetais pesquisadas por este programa, a partir da sistematização e análise do acervo documental do PPPM depositado no Ministério da Saúde. Como critério para a seleção das plantas, foram escolhidas espécies de todas as regiões do Brasil e, entre elas, as mais utilizadas popularmente, tendo sido avaliada a farmacologia e a toxicologia do extrato bruto da planta. Segundo o Ministério da Saúde (2006):

Das 74 espécies vegetais selecionadas para a realização de estudos, 55 foram pesquisadas, correspondendo a $74,3 \%$ do total proposto. Em relação às espécies pesquisadas, 50 delas $(90,9 \%)$ foram submetidas a ensaios de farmacologia préclínica; já outras $15(27,2 \%)$ chegaram a ensaios clínicos e 30 (54,5\%) foram avaliadas toxicologicamente. Das 15 espécies submetidas a ensaios clínicos, em pelo menos $9(60 \%)$ confirmaram as ações atribuídas popularmente ( $p$ 118).

As informações contidas nos documentos oficiais em relação as espécies pesquisadas e comprovadas, assim como outras informações relevantes que envolvem as pesquisas com plantas medicinais muitas vezes divergem em dados e datas, mostrando que como antes da criação da Política Nacional de Medicinas Tradicionais as informações coletadas eram desordenadas e descontínuas.

${ }^{5}$ Como política pública, a assistência farmacêutica teve início em 1971 através da instituição da Central de Medicamentos (CEME), que tinha como missão a de fornecer medicamentos à população de baixa renda. $A$ CEME se caracterizava por manter uma política centralizada de aquisição e distribuição de medicamentos (MINISTÉRIO DA SAÚDE, 2006). 


\section{RESULTADOS E DISCUSSÃO}

\section{Categorização das plantas encontradas nos Programa de Pesquisas de Plantas Medicinais}

A partir dos resultados das pesquisas do PPPM foi realizado um levantamento de artigos publicados nos últimos anos, visando apresentar o avanço das pesquisas científicas destas espécies e/ou de recomendações que apoiem o seu uso ou não (MINISTÉRIO DA SAÚDE, 2006b). Partindo da análise dessas espécies vamos aqui categorizar as que tiveram comprovadas a não toxidade bem como a sua eficácia através do seu uso popular.

As pesquisas com plantas medicinais continuaram sendo realizadas e em março de 2009 o Ministério da Saúde lançou a relação de plantas medicinais de interesse ao SUS (RENISUS), no total de 71 espécies (MINISTÉRIO DA SAÚDE, 2009). E ainda foram apresentadas 9 espécies aprovadas para uso pela ANVISA, (algumas já comprovadas pela PPPM anteriormente) e com potencial para a fabricação de medicamentos fitoterápicos, sendo elas: Alcachofra (Cynara scolymus), Aroeira (Schinus terebentthifolius), Cáscara sagrada (Rhamnus purshiana), Garra do diabo (Harpagophytum procumbens), Guaco (Mikania laevigata), Unha de gato (Uncaria tomentosa) e o composto isoflavona de soja (ANVISA, 2017; MINISTÉRIO DA SAÚDE, 2009).

Em 2011 a ANVISA publicou o formulário de fitoterápicos farmacopéia brasileira constando diversos trabalhos acadêmicos sobre as plantas medicinais e fitoterápicos. O formulário apresentou resultados de pesquisas sobre algumas plantas e suas diversidades de uso tanto sendo erva in natura como do fitoterápico produzido a partir dela (ANVISA, 2011). As espécies pesquisadas foram diversas, assim como a utilização nas unidades de saúde das diferentes regiões do Brasil, devido a diversas culturas e transmissão do conhecimento das espécies, áreas de distribuições geográfica e ecossistemas de ocorrência das espécies.

O Ministério da Saúde (2016) informou ainda que no ano de 2015 houve o registro de 2.160 Unidades Básicas de Saúde no Brasil que disponibilizavam fitoterápicos ou plantas medicinais, sendo que 260 unidades básicas disponibilizavam planta in natura e, em 188 outras unidades a droga vegetal. Também, em 333 unidades de saúde haviam fitoterápicos manipulados e em 1.647 das 2.160 unidades se encontravam o medicamento fitoterápico industrializado.

Apresentaremos a seguir 9 espécies (ver quadro 1) que tiveram seus usos populares confirmados e não apresentaram toxidade nas pesquisas do PPPM6. Após a seleção das espécies, indicaremos seu nome popular e categorizamos conquanto a sua origem, diversidade de usos, áreas de distribuição geográfica e ecossistemas de ocorrência. No que tange a diversidade de uso, utilizaremos as análises disponíveis no documento do PPPM. Em relação à distribuição geográfica e ecossistema de ocorrência consultamos o portal Flora do Brasil, com exceção do Allium sativum (alho) que por se tratar de uma espécie exótica não está disponível naquele portal. Assim, recorremos a diversas fontes externas para realizarmos a caracterização dessa espécie. A categorização de plantas medicinais comprovadas pelo PPPM encontra-se nos quadros 1 e 2 e a sua ilustração na figura 3.

Conforme Silva (et. al., 2006), nas duas últimas décadas alguns estados e municípios vêm desenvolvendo programas de fitoterapia nas unidades de saúde como alternativa à carência de medicamentos alopáticos disponíveis para a população. A política de assistência farmacêutica é um dos recursos do sistema público de saúde que não supre as necessidades de todas as regiões do Brasil, em especial nas regiões Norte e Nordeste. A experiência pioneira que serviu de modelo para todo o Nordeste e posteriormente outras regiões do país, foi o programa Farmácia Viva, desenvolvido no estado do Ceará e considerado exitoso devido o acesso da população mais carente aos medicamentos.

6 Disponível no documento "A Fitoterapia no SUS e o Programa de Pesquisa de Plantas Medicinais" (MINISTÉRIO DA SAÚDE, 2006B) 
Quadro 1: Categorização das espécies comprovadas pela PPPM

\begin{tabular}{|l|l|l|l|}
\hline Espécie & Nome popular & Origem & Diversidade de uso \\
\hline Allium sativum & Alho & Exótica & $\begin{array}{l}\text { Anti-hipertensiva, verminose e parasitoses } \\
\text { intestinais }\end{array}$ \\
\hline Schinus terebentthifolius & Aroeira & Nativa & Cistite, infecções vaginais \\
\hline Cecropi glaziovi Snethlage & Embaúba & Nativa & Anti-hipertensiva \\
\hline Maytenus ilicifolia & Espinheira santa & Nativa & Ação gástrica, antiulceral \\
\hline Mikania laevigata & Guaco & Nativa & Afecções respiratórias \\
\hline Ageratum conyzoides & Mentrasto & Nativa & Analgésica, tratamento de artrose \\
\hline Boerhavia diffusa & Pega pinto & Nativa & Redução de metástase \\
\hline Uncaria tomentosa & Unha-de-gato & Nativa & Inflamações e enfermidades degenerativas \\
\hline Phyllanthus & Quebra-pedra & Nativa & Cálculo renal \\
\hline
\end{tabular}

Fonte: FLORA DO BRASIL (2018) e MINISTÉRIO DA SAÚDE (2006). (Elaboração dos autores, 2018)

Quadro 2: Distribuição geográfica e ecossistêmica de ocorrência comprovadas pela PPPM

\begin{tabular}{|c|c|c|}
\hline Nome popular & Distribuição geográfica & Ecossistema de ocorrência \\
\hline Alho & Ásia Central & $\begin{array}{l}\text { Pastagens temperadas, savanas e matos, pradarias de } \\
\text { montanha, matos xerófitas, florestas temperadas de } \\
\text { coníferas }\end{array}$ \\
\hline Aroeira & $\begin{array}{l}\text { Nordeste (Alagoas, Bahia, Ceará, } \\
\text { Paraíba, Pernambuco, Rio Grande do } \\
\text { Norte, Sergipe) } \\
\text { Centro-Oeste (Mato Grosso do Sul) } \\
\text { Sudeste } \\
\text { Sul }\end{array}$ & $\begin{array}{l}\text { Cerrado, floresta ciliar ou galeria, floresta estacional } \\
\text { semidecidual, floresta ombrófila mista, floreta pluvial, } \\
\text { manguezal, restinga }\end{array}$ \\
\hline Embaúba & $\begin{array}{l}\text { Norte } \\
\text { Nordeste (Alagoas, Bahia, Ceará, } \\
\text { Maranhão, Pernambuco) } \\
\text { Centro-Oeste (Mato Grosso) } \\
\text { Sudeste } \\
\text { Sul (Paraná, Santa Catarina) }{ }^{1}\end{array}$ & $\begin{array}{l}\text { Floresta Ciliar ou Galeria, Floresta de Terra Firme, Floresta } \\
\text { de Várzea, Floresta Estacional Semidecidual, Floresta } \\
\text { Ombrófila (Floresta Pluvial), Restinga }{ }^{1}\end{array}$ \\
\hline Espinheira santa & $\begin{array}{l}\text { Sudeste (Minas Gerais, Rio de } \\
\text { Janeiro, São Paulo) } \\
\text { Sul }\end{array}$ & $\begin{array}{l}\text { Floresta Ciliar ou Galeria, Floresta Estacional Semidecidual, } \\
\text { Floresta Ombrófila (Floresta Pluvial), Vegetação Sobre } \\
\text { Afloramentos Rochoso }^{1}\end{array}$ \\
\hline Guaco & $\begin{array}{l}\text { Nordeste (Bahia) } \\
\text { Centro-Oeste (Mato Grosso do Sul) } \\
\text { Sudeste } \\
\text { Sul }\end{array}$ & $\begin{array}{l}\text { Cerrado (lato sensu), Floresta Ciliar ou Galeria, Floresta } \\
\text { Ombrófila (Floresta Pluvial), Floresta Ombrófila Mista }\end{array}$ \\
\hline Mentrasto & Todo o Brasil & $\begin{array}{l}\text { Área Antrópica, Caatinga (stricto sensu), Campinarana, } \\
\text { Campo de Altitude, Campo de Várzea, Campo Limpo, } \\
\text { Campo Rupestre, Carrasco, Cerrado (lato sensu), Floresta } \\
\text { Ciliar ou Galeria, Floresta de Igapó, Floresta de Terra } \\
\text { Firme, Floresta de Várzea, Floresta Estacional Decidual, } \\
\text { Floresta Estacional Perenifólia, Floresta Estacional } \\
\text { Semidecidual, Floresta Ombrófila (Floresta Pluvial), Floresta } \\
\text { Ombrófila Mista, Manguezal, Palmeiral, Restinga, Savana } \\
\text { Amazônica, Vegetação Aquática, Vegetação Sobre } \\
\text { Afloramentos Rochosos }\end{array}$ \\
\hline Pega pinto & Nordeste (Ceará) & Caatinga \\
\hline Unha-de-gato & $\begin{array}{l}\text { Norte (Acre) } \\
\text { Centro-Oeste (Mato Grosso e Mato } \\
\text { Grosso do Sul) }\end{array}$ & $\begin{array}{l}\text { Floresta Ciliar ou Galeria, Floresta Estacional Perenifólia, } \\
\text { Floresta Estacional Semidecidual }\end{array}$ \\
\hline Quebra- pedra & Todo o Brasil & $\begin{array}{l}\text { Antrópica, Caatinga (stricto sensu), Campinarana, Campo } \\
\text { de Altitude, Campo de Várzea, Campo Limpo, Campo } \\
\text { Rupestre, Carrasco, Cerrado (lato sensu), Floresta Ciliar ou } \\
\text { Galeria, Floresta de Igapó, Floresta de Terra Firme, Floresta } \\
\text { de Várzea, Floresta Estacional Decidual, Floresta } \\
\text { Estacional Perenifólia, Floresta Estacional Semidecidual, } \\
\text { Floresta Ombrófila (Floresta Pluvial), Floresta Ombrófila } \\
\text { Mista, Manguezal, Palmeiral, Restinga, Savana Amazônica, } \\
\text { Vegetação Aquática, Vegetação Sobre Afloramentos } \\
\text { Rochosos }\end{array}$ \\
\hline
\end{tabular}

Fonte: FLORA DO BRASIL (2018) e MINISTÉRIO DA SAÚDE (2006). (Elaboração dos autores, 2018) 
Figura 3: Espécies comprovadas pelo PPPM

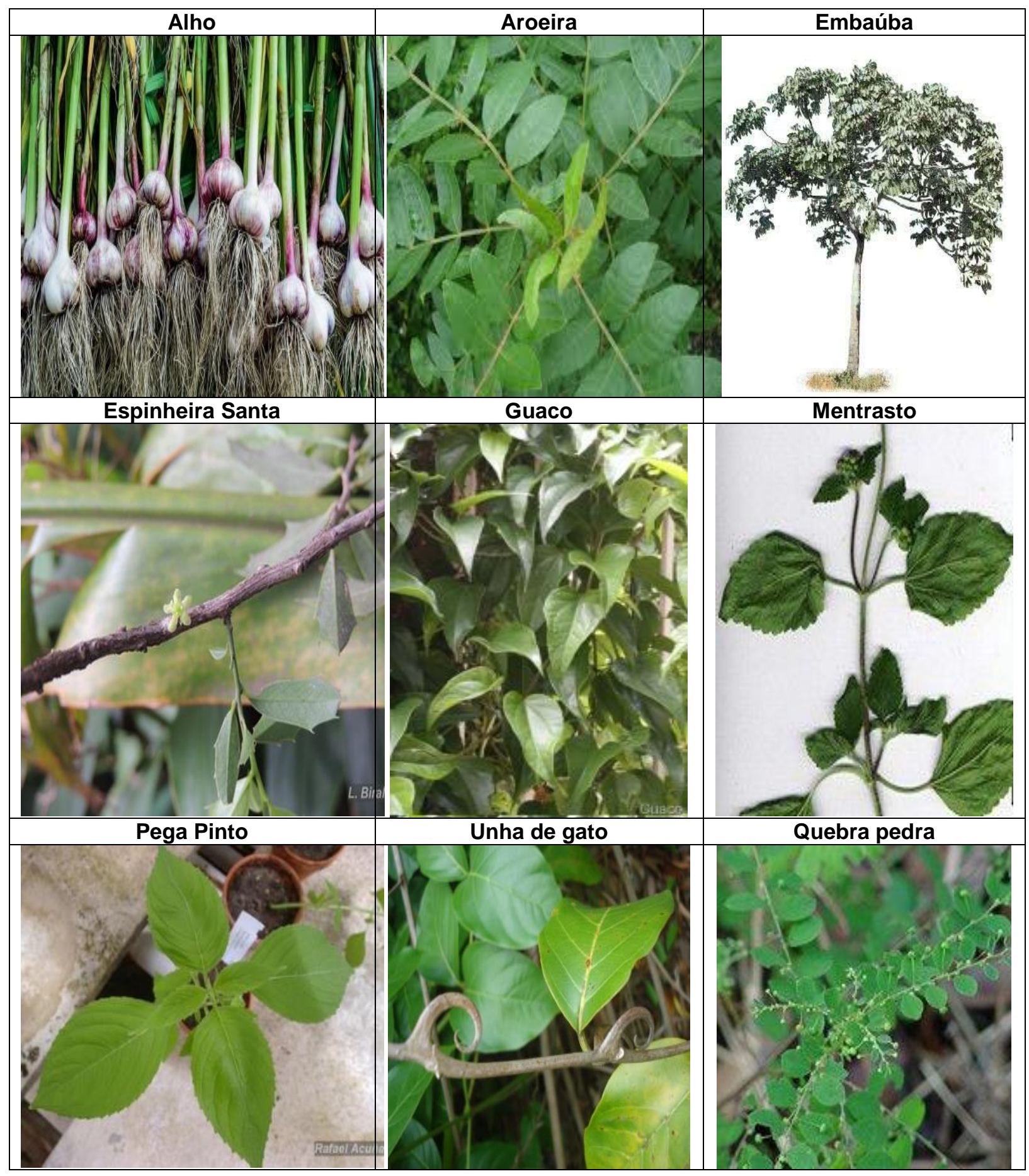

Fonte: FLORA DO BRASIL (2018) e Botsaris (1995). (Elaboração dos autores, 2018)

As espécies acima tiveram o seu uso popular comprovado pela PPPM (ver quadro 1), na realidade são utilizadas por muitos anos pela população brasileira tendo, a comprovação empírica de suas eficácias. Trazem como características em suas diversidades de uso o alívio/tratamento e por vezes a cura de sintomas que ocasionam procura por profissionais e medicamentos nas unidades de saúde. O uso seguro das plantas pesquisadas como possibilidade de atenuar as filas em unidades de atenção primária foram um dos objetivos da implementação da Política Nacional de Plantas Medicinais e Fitoterápicos (BRASIL, 2006). 
A institucionalização desta prática popular e tradicional enquanto política pública utiliza dos mesmos métodos científicos da medicina moderna para comprovar sua eficácia, transformando o significado do que antes foi uma ferramenta importante para cuidados com a saúde testada através do tempo e por populações que possuem a sabedoria do uso das plantas medicinais, para um potencial recurso de desenvolvimento da indústria farmacêutica nacional.

Conforme os quadros 1 e 2, como critério para a seleção das espécies a CEME, e posteriormente o PPPM, consideraram as plantas que apresentavam tradição e coincidência da indicação em diversas regiões do país para os mesmos sintomas. Plantas que possuíam uma ampla distribuição geográfica, facilidade de cultivos, espécies que serviam de alternativa no tratamento de doenças de maior significância socioeconômica. Em relação aos critérios de ordem médicas não foram incluídas espécies que possuíam como indicação sintomas ou doenças não comprovadas pela medicina. $O$ PPPM priorizou o estudo de espécies que atuavam nos sintomas de dor e inflamação e nos distúrbios gastrintestinais, respiratórios, cardiovasculares e nervosos (MINISTÉRIO DA SAÚDE, 2006b).

As pesquisas com plantas medicinais continuam sendo realizadas e a inclusão desta prática nas unidades de atenção primária da saúde consideram o saber popular sobre os remédios caseiros e os conhecedores deste saber para uso medicinal e seleção de plantas para pesquisa com o objetivo de comprovar as indicações de uso popular, eficácia e toxidade das espécies indicadas e utilizadas por essas pessoas, que chegaram ao conhecimento sobre a utilização das plantas de forma oral, atravessando gerações. A figura 3 ilustra as nove espécies que tiveram sua eficácia comprovadas a partir do uso popular.

Observamos que as espécies estudadas e comprovadas em relação ao uso popular e a não toxidade atuam em enfermidades e sintomas comuns na população brasileira (ver figura 3) e com demanda para atenção básica como: analgesia, distúrbio gástrico e intestinais, hipertensão, assim como estratégias para o tratamento preventivo, um dos principais objetivos das unidades de atenção primária na saúde mantidas pelo SUS.

\section{CONSIDERAÇÕES FINAIS}

Apresentamos no decorrer do texto a trajetória do uso das plantas medicinais e práticas populares difundida no país. Começamos a nossa análise no período colonial, onde os colonizadores se aproximaram de elementos da cultura local, apropriaram-se dela e posteriormente impuseram a sua cultura como modelo a ser seguido, o que reverberou também nas práticas e tratamento a enfermidades.

No que tange ao campo da saúde, essa imposição se tornou preponderante a partir do século XVIII, com o cientificismo, a modernidade e a enorme expansão tecnológica da medicina europeia, ou medicina moderna. As demais medicinas, de outras culturas, como por exemplo: a Medicina Tradicional Chinesa, Indiana, Indígena e o próprio uso das plantas medicinais foram postos em dúvida em relação a sua eficácia devido à falta de comprovações científicas, muito embora fossem comprovadas durante um longo período de tempo através dos seus múltiplos usos.

Nas décadas de 1960 e 1970, época de diversos movimentos sociais, incluindo a luta por melhores condições de saúde da população, a procura pelas práticas integrativas na saúde cresceu e entre elas o maior uso das plantas medicinais. A prática de uso de plantas medicinais resistiu à modernidade, ao cientificismo e a expansão tecnológica da medicina moderna por continuar sendo muitas vezes a única alternativa de cuidado e autocuidado para populações com acesso restrito aos serviços públicos de saúde, principalmente nos países periféricos.

Esta prática popular utilizada no Brasil desde antes da colonização foi institucionalizada, tendo o seu uso popular comprovado através de métodos da ciência moderna e após a sua comprovação passaram a ser interessantes para a indústria farmacêutica. Por outro lado, a inclusão das plantas medicinais no SUS e a criação da Política Nacional de Plantas Medicinais e Fitoterápicos têm potencial para gerar transformações no campo da saúde, por ser mais uma opção de tratamento que carrega um significado de cura, prevenção e tratamento diferente das práticas médicas convencionais, cada vez mais baseadas no uso intensivo de tecnologias nas suas práticas. 


\section{REFERÊNCIAS}

ALHO, C. Importância da Biodiversidade para a saúde humana: uma perspectiva ecológica. Rev. estudos avançados, 26 (74), 2012. Disponível em:

<http://www.scielo.br/pdf/ea/v26n74/a11v26n74.pdf>. Acesso em 08 de dezembro de 2018. https://doi.org/10.1590/S0103-40142012000100011

ANVISA. Lista DCB Plantas medicinais atualizada em 2017. 2017. Disponível em:

$<$ http://portal.anvisa.gov.br/resultado-de-

busca?p_p_id=101\&p_p_lifecycle=0\&p_p_state=maximized\&p_p_mode=view\&p_p_col_id=column$1 \& p \_p \_c o l \_c o u n t=1 \& \_101$ struts_action=\%2Fasset_publisher\%2Fview_content $\&$ _101_assetEntryld= 3881905\&_101_type=document>. Acesso em 08 de dezembro de 2018.

BIODIVERSIDADE. Biomas do Brasil. 2018. Disponível em:

$<$ <ttp://www.biodiversidade.rs.gov.br/arquivos/1161807794biomas_br.jpg>. Acesso em 08 de dezembro de 2018.

BLAJ. I. e MALUF. M. Caminhos e fronteiras: o movimento na obra de Sérgio Buarque de Holanda. R. História, São Paulo, n. 122, p. 17-46, jan/jun. 1990. Disponível em:

$<$ http://www.revistas.usp.br/revhistoria/article/view/18619/20682>. Acesso em 08 de dezembro de 2018. https://doi.org/10.11606/issn.2316-9141.v0i122p17-46

BRASIL. Política Nacional de Práticas Integrativas e Complementares no SUS. Brasília: 2006. Disponível em: <http://189.28.128.100/dab/docs/publicacoes/geral/pnpic.pdf>. Acesso em 08 de dezembro de 2018.

CMDSS. Conferência Mundial sobre Determinantes Sociais da Saúde. Declaração Alma-Ata, 2011. Disponível em: <http://cmdss2011.org/site/wp-content/uploads/2011/07/Declara\%C3\%A7\%C3\%A3oAlma-Ata.pdf>. Acesso em 08 de dezembro de 2018.

DIEGUES. A. C (org.), ARRUDA, R. S. V., SILVA, V. C. F., FIGOLS, F. A. B. e ANDRADE, D. Biodiversidade e comunidades tradicionais no Brasil. São Paulo: NUPAUB-USP/PROBIOMMA/CNPq, 1999. Disponível em:

<http://livroaberto.ibict.br/bitstream/1/750/2/Biodiversidade\%20e\%20comunidades\%20tradicionais\%2 Ono\%20Brasil.pdf>. Acesso em 08 de dezembro de 2018.

DONATELLI, M. A necessidade da certeza na explicação cientifica cartesiana e o recurso à experiência. Ilhéus: Cadernos de História e filosofia da ciência, 2003. Disponível em: $<$ https://www.cle.unicamp.br/eprints/index.php/cadernos/article/view/698>. Acesso em 08 de dezembro de 2018.

FARNSWORTH, N. R. Screening plants for new medicines. In: WILSON, E. O. (Ed.) biodiversity. Washington DC: National Academy Press, 1988. pp. 83-97

FERREIRA, L. O. A emergência da medicina tradicional indígena no campo das políticas públicas. Hist. cienc. Saúde Manguinhos. Rio de Janeiro: v. 20, n. 1, p. 203-219, 2013. Disponível em: $<$ http://www.scielo.br/scielo.php?script=sci_arttext\&pid=S0104$59702013000100011 \& \operatorname{lng}=$ en\&nrm=iso $>$. Acesso em 08 de dezembro de 2018. https://doi.org/10.1590/S0104-59702013000100011

FIGUEIREDO, F. F. A agenda político-ambiental no Brasil. Revista Espaço Acadêmico, v. 18, p. 106-115, 2018. Disponível em <http://www.periodicos.uem.br/ojs/index.php/EspacoAcademico/article/view/41075>. Acesso em 08 de dezembro de 2018.

FLORA DO BRASIL. 2018. Disponível em: <http://floradobrasil.jbrj.gov.br/>. Acesso em 08 de dezembro de 2018.

FOUCAULT, M. A Microfísica do Poder. São Paulo: Paz e Terra, 1978. Disponível em: <https://www.nodo50.org/insurgentes/biblioteca/A_Microfisica_do_Poder_-_Michel_Foulcault.pdf>. Acesso em 07 de julho de 2018.

FREITAS, S. M. A Saúde no Brasil: do descobrimento aos dias atuais. São Paulo; INDHS. 2014 GANEM, R.S. Conservação da biodiversidade: Legislação e políticas públicas. Brasília, 
Edições Câmara, 2010. 437p Disponível em:

$<$ https://livraria.camara.leg.br/index.php?_route_=livros/livros-impressos/conservac-o-dabiodiversidade.html>. Acesso em 07 de julho de 2018.

LANDER. E. A colonialidade do saber: eurocentrismo e ciências sociais perspectivas latino americanas. Buenos Aires: Clacso, 2005. Disponível em

$<$ https://edisciplinas.usp.br/pluginfile.php/2591382/mod_resource/content/1/colonialidade_do_saber_e urocentrismo_ciencias_sociais.pdf $>$. Acesso em 08 de dezembro de 2018.

LUZ, M. T. Cultura contemporânea e medicinas alternativas: novos paradigmas em saúde no final do século XX. Rev. estudos avançados. Disponível em

<https://www.scielosp.org/article/physis/2005.v15suppl0/145-176/>. Acesso em 08 de dezembro de 2018. https://doi.org/10.1590/S0103-73312005000300008

MINISTÉRIO DA SAÚDE. Mais 10 práticas integrativas são inseridas na PNPIC. Brasília: 2018. Disponível em <http://dab.saude.gov.br/portaldab/noticias.php?conteudo=_\&cod=2872>. Acesso em 08 de dezembro de 2018.

Programa Nacional de Plantas Medicinais e Fitoterápicos. Brasília: 2008. Disponível em <http://bvsms.saude.gov.br/bvs/saudelegis/gm/2008/pri2960_09_12_2008.html>. Acesso em 08 de dezembro de 2018.

Política Nacional de Plantas Medicinais e Fitoterápicos. Brasília: 2006. Disponível em <http://bvsms.saude.gov.br/bvs/publicacoes/politica_nacional_fitoterapicos.pdf>. Acesso em $08 \mathrm{de}$ dezembro de 2018.

A fitoterapia no SUS e o Programa de Pesquisa de Plantas Medicinais da Central de Medicamentos. 2006b. Disponível em $<$ http://bvsms.saude.gov.br/bvs/publicacoes/fitoterapia_no_sus.pdf>. Acesso em 08 de dezembro de 2018.

Política Nacional de Práticas Integrativas e Complementares. Brasília: 2005.

Disponível em <http://bvsms.saude.gov.br/bvs/saudelegis/gm/2006/prt0971_03_05_2006.html>. Acesso em 08 de dezembro de 2018.

OMS. Estrategia de la OMS sobre medicina tradicional 2014-2023. Organização Mundial de Saúde, 2014. Disponível em <http://apps.who.int/iris/bitstream/handle/10665/95008/9789243506098_spa.pdf;jsessionid=D65AD1D CC04CCF0044B61351F97DBB72? sequence=1 >. Acesso em 08 de dezembro de 2018.

PAIM, J. S. Reforma Sanitária Brasileira: contribuição para a compreensão e crítica. Rio de Janeiro: FIOCRUZ, 2008. Disponível em: <http://books.scielo.org/id/4ndgv/pdf/paim-9788575413593.pdf>. Acesso em 08 de dezembro de 2018. https://doi.org/10.7476/9788575413593

QUEIROZ, M. D. S. O paradigma mecanicista da medicina ocidental moderna: uma perspectiva antropológica. Revista de saúde pública, 20, 309-317, 1986. Disponível em $<$ http://www.scielo.br/scielo.php?pid=S0034-89101986000400007\&script=sci_abstract\&tlng=pt>. Acesso em 08 de dezembro de 2018. https://doi.org/10.1590/S0034-89101986000400007

SAAD, M. e LIMA, P. T. Acesso às terapias complementares cresce no SUS. Einstein: Educ. Contin. Saúde, 2010. Disponível em <http://apps.einstein.br/revista/arquivos/PDF/1883-EC_V8_N4_p21011.pdf>. Acesso em 08 de dezembro de 2018.

STADEN, Hans. Duas viagens ao Brasil: primeiros registros sobre o Brasil. Porto Alegre: L\&PM Pocket, 2010.

TABARELLI. M, AGUIAR, A. V., RIBEIRO, M. C., METZGER, J. P., PERES, C. A. Prospects for biodiversity Conservation in the Atlantic Forest Lessons from aging human modified landscape. Elsevier. pp: 2226- 3340. 2010. Disponível em:

<https://www.sciencedirect.com/science/article/abs/pii/S0006320710000443>. Acesso em 08 de dezembro de 2018. 